\title{
State of global pediatric neurosurgery outreach: survey by the International Education Subcommittee
}

\author{
Matthew C. Davis, MD, ${ }^{1}$ Brandon G. Rocque, MD, MS, ${ }^{1}$ Ash Singhal, MD, ${ }^{2}$ Thomas Ridder, MD, ${ }^{3}$ \\ Jogi V. Pattisapu, MD, ${ }^{4}$ and James M. Johnston Jr., MD ${ }^{1}$

\begin{abstract}
'Department of Neurosurgery, University of Alabama at Birmingham, Alabama; '2Department of Neurosurgery, BC Children's Hospital, Vancouver, British Columbia, Canada; ${ }^{3}$ Department of Neurosurgery, Virginia Commonwealth University, Richmond, Virginia; and ${ }^{P}$ Pediatric Neurosurgery, University of Central Florida College of Medicine, Orlando, Florida
\end{abstract}

\begin{abstract}
OBJECTIVE Neurosurgical services are increasingly recognized as essential components of surgical care worldwide. The degree of interest among neurosurgeons regarding international work, and the barriers to involvement in global neurosurgical outreach, are largely unexplored. The authors distributed a survey to members of the American Association of Neurological Surgeons/Congress of Neurological Surgeons (AANS/CNS) Joint Section on Pediatric Neurosurgery to assess the state of global outreach among its members and to identify barriers to involvement.
\end{abstract}

METHODS An internet-based questionnaire was developed by the International Education Subcommittee of the AANS/ CNS Joint Section on Pediatric Neurosurgery and distributed to pediatric neurosurgeons via the AANS/CNS Joint Section email contact list. Participants were surveyed on their involvement in global neurosurgical outreach, geographic location, nature of the participation, and barriers to further involvement.

RESULTS A 35.3\% response rate was obtained, with 116 respondents completing the survey. Sixty-one percent have performed or taught neurosurgery in a developing country, and $49 \%$ travel at least annually. Africa was the most common region (54\%), followed by South America (30\%), through 29 separate organizing entities. Hydrocephalus was the most commonly treated condition (88\%), followed by spinal dysraphism (74\%), and tumor (68\%). Most respondents obtained follow-up through communications from local surgeons (77\%). Seventy-one percent believed the international experience improved their practice, and $74 \%$ were very or extremely interested in working elsewhere. Interference with current practice $(61 \%)$, cost $(44 \%)$, and difficulty identifying international partners $(43 \%)$ were the most commonly cited barriers to participation.

CONCLUSIONS Any coordinated effort to expand global neurosurgical capacity begins with appreciation for the current state of outreach efforts. Increasing participation in global outreach will require addressing both real and perceived barriers to involvement. Creation and curation of a centralized online database of ongoing projects to facilitate coordination and involvement may be beneficial.

https://thejns.org/doi/abs/10.3171/2017.3.PEDS16433

KEY WORDS pediatric neurosurgery; global health; socioeconomic

S URGICAL disease makes up one of the top 15 causes of global disability, ${ }^{26}$ yet the role of subspecialty surgical care in global public health has only recently been widely recognized. ${ }^{1,14,27}$ Subspecialty surgical care is unavailable to many in the developing world, ${ }^{35,36}$ but even where facilities exist, insurmountable financial barriers place ready access to care out of reach for many., ${ }^{2,44}$ Despite an increase in the number of neurosurgical training programs worldwide, the gap between neurosurgical ca- pacity and need remains wide. ${ }^{38}$ In some regions, a single pediatric neurosurgeon is burdened with providing care for a population of millions, with coverage areas in the thousands of square miles. ${ }^{12,13}$

Neurosurgical services, particularly in the management of pediatric hydrocephalus and trauma, are increasingly recognized as essential components of surgical care worldwide, ${ }^{25,39}$ and the sustained presence of visiting surgical teams can have a meaningful impact on local capac-

ABBREVIATIONS AANS/CNS = American Association of Neurological Surgeons/Congress of Neurological Surgeons; FIENS = Foundation for International Education in Neurological Surgery; WFNS $=$ World Federation of Neurosurgical Societies.

SUBMITTED September 1, 2016. ACCEPTED March 10, 2017.

INCLUDE WHEN CITING Published online May 19, 2017; DOI: 10.3171/2017.3.PEDS16433. 
ity building. ${ }^{19,43}$ However, the degree of interest among neurosurgeons regarding international work, and barriers to involvement in global neurosurgical outreach, are largely unexplored. Here we discuss the results of a survey that we distributed to members of the American Association of Neurological Surgeons/Congress of Neurological Surgeons (AANS/CNS) Joint Section on Pediatric Neurosurgery to assess the state of global outreach efforts among North American pediatric neurosurgeons and to identify barriers to involvement.

\section{Methods}

An 11-question, internet-based questionnaire was developed by the International Education Subcommittee of the AANS/CNS Pediatric Section (Table 1). The questionnaire was pilot tested among all members of the International Education Subcommittee, and the survey design and questions included were approved by all members prior to distribution. The questionnaire was distributed to pediatric neurosurgeons in North America via the AANS/ CNS Joint Pediatric Section email listserv. Attending-level pediatric neurosurgeons in North America were asked to complete the survey, whereas other members of the listserv, such as trainees and individuals based outside of North America, were asked to disregard the survey. Reminder emails were sent at 2 weeks and 1 month to initial nonresponders to improve the response rate. Approval was obtained from the Pediatric Section to conduct this survey.

Participants were surveyed on their previous and current involvement in global neurosurgical outreach, geographic location, nature of the participation, and barriers to further involvement. An attempt was made to include both neurosurgeons who had engaged in global neurosurgical outreach and those without prior experience. The following questions allowed binary Yes/No answers without comment: "Have you ever performed or taught neurosurgery in a developing country?" and "Did your family join you during any of these trips?" Geographic region of outreach, organizing entity, mechanism for obtaining postoperative follow-up, conditions treated, and perceived barriers to participation in global neurosurgery projects were assessed using a multiple-choice format in which multiple answers and typed-in comments were allowed. Frequency of outreach was queried using the following options: more than once per year; once per year; every few years; or only occasionally ( 1 or 2 trips ever). Participants were queried on whether their international experience improved their practice or surgical skills and responded via a 5-point Likert scale, in which $1=$ strongly disagree; 2 = disagree; 3 $=$ neutral; $4=$ agree; and $5=$ strongly agree. The same scale was used for the question "To what extent do you agree with the following statement: International training (for 1 month or greater) should be required during neurosurgery residency or pediatric neurosurgery fellowship." Participants were queried on their interest in performing or teaching neurosurgery in the developing world and responded via a 5-point Likert scale, in which $1=$ not at all interested; $2=$ slightly interested; $3=$ moderately interested; $4=$ very interested; and $5=$ extremely interested.
TABLE 1. Questionnaire distributed to AANS/CNS Pediatric Section members

Survey Questions

Have you ever performed/taught neurosurgery in a developing country?

In what regions have you performed/taught neurosurgery in a developing country?

How frequently do you travel internationally to teach or perform neurosurgery?

Was your travel associated with an organizing entity? If so, what entity?

What type of conditions did you primarily treat?

How did you obtain follow up information on patients you treated?

Do you feel that your international experience improved your practice or surgical skills?

Did your family join you during any of these trips?

Are you interested in performing/teaching neurosurgery elsewhere in the world?

In your opinion, what are the major barriers to participation in global neurosurgery projects?

To what extent do you agree with the following statement: International training (for 1 month or greater) should be required during neurosurgery residency or pediatric neurosurgery fellowship

\section{Results}

Of a cohort of 329 active Pediatric Section members, 116 respondents completed the survey, resulting in a $35 \%$ response rate. Seventy-one respondents $(61 \%)$ had performed or taught neurosurgery in a developing country, whereas 45 respondents (39\%) had not. Of these, $49 \%$ traveled at least annually, 22\% every few years, and $29 \%$ had taken only 1 or 2 international trips.

Africa was the most common region where pediatric neurosurgeons had traveled (54\%), followed by South America (30\%), Central America (29\%), and South Asia (22\%). Respondents traveled through a total of 29 separate organizing entities, with CURE Uganda (10 respondents), the World Pediatric Project (5 respondents), and the Foundation for International Education in Neurological Surgery (FIENS; 5 respondents) being the most commonly used agencies. The largest number of respondents worked without any overseeing entity (27 respondents).

Hydrocephalus was the most commonly treated condition (88\%), followed by spinal dysraphism (74\%), tumor (68\%), trauma (37\%), craniofacial (35\%), and spine (26\%). Most respondents obtained follow-up through communication from local surgeons $(77 \%)$, but $21 \%$ received follow-up through local nonneurosurgeon physicians or nurses, and $18 \%$ obtained no follow-up information on the patients they treated. (The values in the previous sentence total more than $100 \%$ because some surgeons obtained follow-up information from multiple sources.)

Seventy-one percent (47 of 66 respondents) agreed or strongly agreed that their international experience improved their practice, and 74\% were at least moderately interested in working in a different region. Twenty-nine percent (19 of 66 respondents) had family members join them 
TABLE 2. Coordinating agencies used by survey respondents

\begin{tabular}{|c|c|}
\hline Coordinating Agencies & No. of Respondents \\
\hline None & 27 \\
\hline CURE Uganda & 10 \\
\hline World Pediatric Project & 5 \\
\hline FIENS & 5 \\
\hline Project Medishare & 4 \\
\hline ISPN & 4 \\
\hline World Medical Mission & 2 \\
\hline BethanyKids & 2 \\
\hline AMPATH Consortium Kenya & 2 \\
\hline WFNS & 1 \\
\hline World Craniofacial Foundation & 1 \\
\hline Visiting Professor & 1 \\
\hline Solidarity Bridge & 1 \\
\hline Smiles International & 1 \\
\hline Shriners & 1 \\
\hline Samaritans Purse & 1 \\
\hline Project Perfect World & 1 \\
\hline Neurosurgery Outreach Foundation & 1 \\
\hline Maghreb-American Health Foundation & 1 \\
\hline Local Government & 1 \\
\hline INCA & 1 \\
\hline Indian Society of Pediatric Neurosurgery & 1 \\
\hline Healing the Children & 1 \\
\hline HaitiHealthyKids & 1 \\
\hline Global Neuro Rescue & 1 \\
\hline ESPN & 1 \\
\hline Children's of Alabama Global Health & 1 \\
\hline Children's China Foundation & 1 \\
\hline ASPN & 1 \\
\hline AANS/CNS Pediatric Section & 1 \\
\hline
\end{tabular}

AMPATH = Academic Model Providing Access to Healthcare; ASPN = American Society of Pediatric Neurosurgeons; ESPN = European Society for Pediatric Neurosurgery; INCA = International Neurosurgical Children's Association; ISPN = International Society for Pediatric Neurosurgery.

on at least one outreach trip. Additionally, 31\% (33 of 107 respondents) either agreed or strongly agreed that international neurosurgical experiences of more than 1-month duration should be a required component of a neurosurgical residency or pediatric neurosurgery fellowship.

Interference with current practice $(61 \%, 62$ of 101 respondents), cost (44\%), difficulty identifying international partners (43\%), and lack of supporting team and/or equipment (38\%) were the most commonly cited barriers to participation. Table 2 demonstrates the full range of coordinating agencies used by survey respondents, and Table 3 lists typed-in comments made in response to questioning on the most significant barriers to participation in global neurosurgical outreach. Figure 1 displays current regions of activity, the scope of neurosurgical practice and patient follow-up, and perceived barriers to global neurosurgical practice among survey respondents.
TABLE 3. Comments on top barriers to global neurosurgical outreach

\begin{tabular}{|c|}
\hline Comment \\
\hline $\begin{array}{l}\text { Funding is always a problem but family needs of team members is } \\
\text { significant. }\end{array}$ \\
\hline $\begin{array}{l}\text { I would only go somewhere where I could teach a surgeon to perform } \\
\text { surgery. I have no interest in medical tourism. }\end{array}$ \\
\hline $\begin{array}{l}\text { Reaction from fully trained and even foreign trained (US/North } \\
\text { America/Europe) local neurosurgeons. }\end{array}$ \\
\hline $\begin{array}{l}\text { Finding a way to make a meaningful contribution given limited time of } \\
\text { provider and unknown needs of local population. }\end{array}$ \\
\hline $\begin{array}{l}\text { It would take months, not a week or two, to transform thinking and } \\
\text { practices in many situations. }\end{array}$ \\
\hline Coverage while I am away. \\
\hline $\begin{array}{l}\text { Concerns about ethics and whether in some cases it's more for "us" } \\
\text { than for "them" - big picture considerations. }\end{array}$ \\
\hline $\begin{array}{l}\text { Not understanding the political/social system and the degree of } \\
\text { personal/family risk. }\end{array}$ \\
\hline General travel risk for US citizens. Kidnapping, terrorism, and so on. ${ }^{*}$ \\
\hline Lack of coordination among NGOs and providers. \\
\hline Family support. \\
\hline Inability to do real follow-up, difficulty mentoring after return home. \\
\hline $\begin{array}{l}\text { So little can really be done, and usually the medical problems related } \\
\text { to infectious disease and clean water are far more significant than } \\
\text { neurosurgery. }\end{array}$ \\
\hline Time away from family. $\dagger$ \\
\hline Haven't been invited to participate. \\
\hline Attitudinal issues among local neurosurgeons. $\dagger$ \\
\hline
\end{tabular}

\section{Discussion}

Here we report survey findings from 116 pediatric neurosurgeons in North America, to assess the current state of international outreach efforts and to identify potential barriers to further engagement. Our results included participants with extensive and those with no international experience. Although our findings are not necessarily reflective of the overall population of practicing pediatric neurosurgeons in the US, they provide valuable guidance on mechanisms to improve and facilitate neurosurgical outreach efforts.

The current state of global neurosurgical outreach is fragmented, with respondents traveling through 29 separate organizing entities. By way of context, the American Society of Pediatric Neurosurgeons currently has only 164 active members (https://www.aspn.org). It is also telling that the largest number of respondents worked without the benefit of an overseeing entity. This is consistent with our observation that difficulty identifying international partners, and the lack of a supporting team, were frequently cited barriers to participation.

There is growing interest among neurosurgical residency program directors to offer global neurosurgical experiences in their curriculum, as a mechanism to attract 

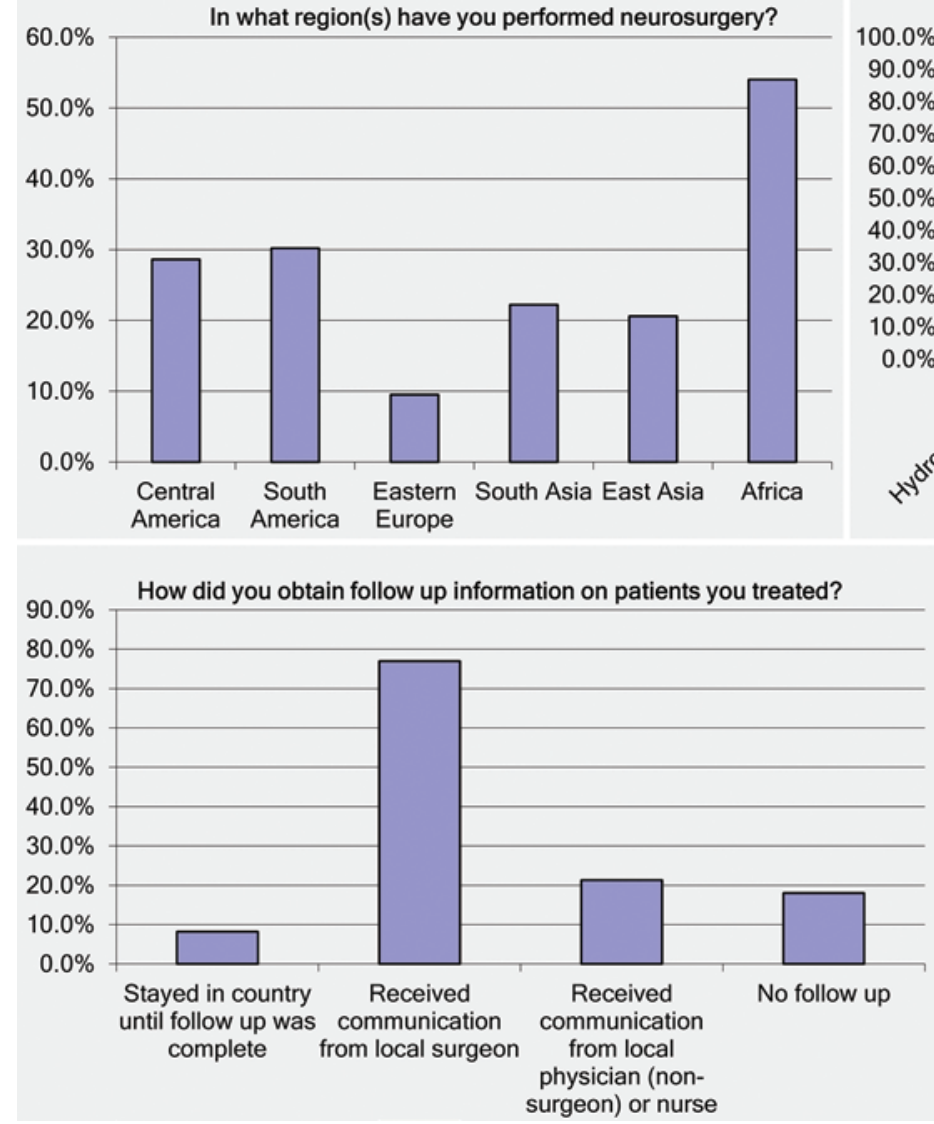

What type of conditions did you primarily treat? (pick all that apply)

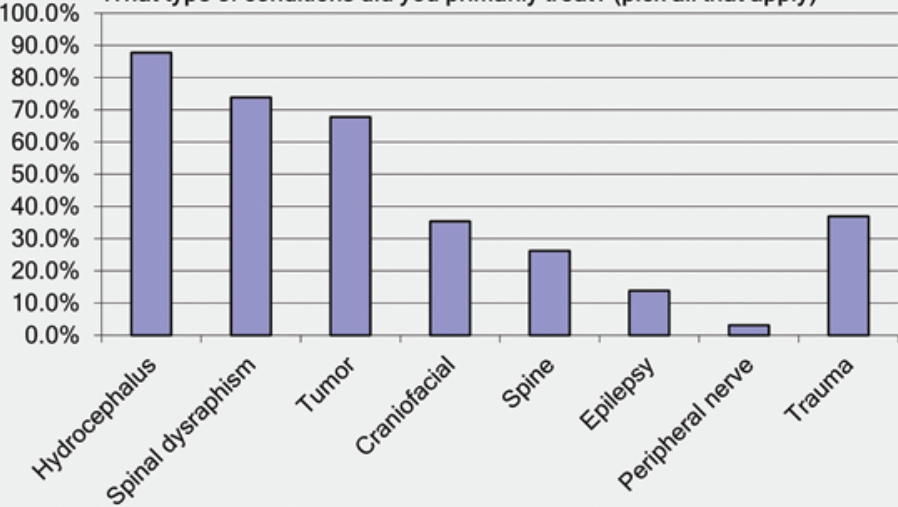

In your opinion, what are the major barriers to participation in global neurosurgery projects?

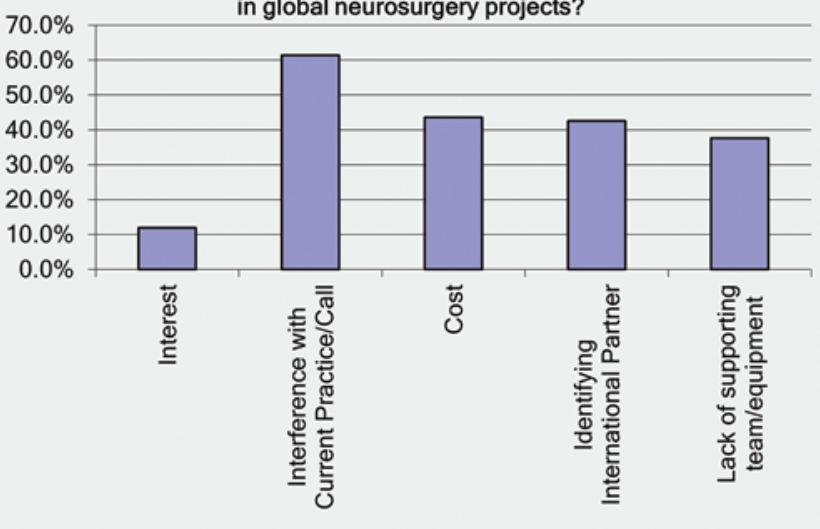

FIG. 1. Bar graphs showing current regions of activity, scope of neurosurgical practice and patient follow-up, and perceived barriers to global neurosurgical practice among survey respondents. Figure is available in color online only.

top residency applicants. ${ }^{33}$ Interestingly, only $31 \%$ of our respondents either agreed or strongly agreed that extended international training experiences should be required for all neurosurgical residents or pediatric neurosurgical fellows. This low value may reflect perceived loss of critical training time, when programs are already limited by Accreditation Council for Graduate Medical Education (ACGME) work-hour restrictions. Ethical considerations surrounding the appropriate role of trainees in low-resource settings may also be a contributing factor. ${ }^{34}$

\section{Additional Barriers to International Efforts}

The FIENS is one of the largest groups directing global neurosurgical outreach, working to provide hands-on training, didactics, and infrastructure to neurosurgeons at more than 20 sites on 6 continents, predominantly through trips lasting less than 1 month. ${ }^{3,8}$ Analysis of 178 FIENS volunteer reports indicated that successful strategies for global neurosurgical efforts included local collaboration and continuity of care, while equipment and infrastructure frailty were the most commonly cited challenges. ${ }^{33}$ Culture challenges, including language barriers and decreased operative time during holidays, were far less frequently cited. Interestingly, this study only evaluated reports from volunteers who had completed at least a 4-week trip, representing a very small subset of total neurosurgical outreach efforts. These experienced providers saw far different challenges than our study population, which included all pediatric neurosurgeons, ranging from those with many years of global outreach to those with no prior international experience. The challenges these groups appreciated, therefore, were different. It may be that the FIENS respondents were describing barriers to effective neurosurgical care, whereas our respondents were describing barriers to international neurosurgical travels. Whereas long-term FIENS volunteers saw inadequate equipment and infrastructure failure as their primary obstacles, our respondents primarily cited interference with current practice, cost, difficulty identifying international partners, and the lack of a supporting team. Additional typed-in comments emphasized travel risk (5 respondents), reactions from local neurosurgeons (3 respondents), family concerns (4 respondents), and perceived futility (4 respondents).

\section{Effective Training Models and Opportunities for Progress}

Most North America-based neurosurgeons provide international care and training through short-term visits, which have increased dramatically over the past 30 years. ${ }^{37}$ These trips can be highly cost-effective despite the expense of travel and lodging for the visiting surgical team, ${ }^{6}$ but inconsistency in postoperative follow-up 
and lack of emphasis on local capacity building has led to criticism of the short-term mission model. ${ }^{11,21}$

The most compelling mechanism for delivering costeffective pediatric neurosurgical care in the developing world is centered on expanding local capacity. ${ }^{39,40}$ Handson training of local surgeons in their home country by using immersive learning paradigms is of paramount importance to enhancing the effectiveness of short-term neurosurgical brigades. ${ }^{9,20}$ Although neurosurgeons from developing countries may visit North American centers for long-term observerships, in-country training is the most common means of improving local care delivery. Sustainable skill transfer through targeted short-term trips has been demonstrated, ${ }^{10,22}$ and mobile training units can extend equipment and skill transfer beyond the capital cities. ${ }^{32}$ Novel telecollaboration and internet-based tools have also demonstrated potential for continuing education following departure of the visiting surgical team. ${ }^{4,6}$ As an example, HELPLightning, a tablet-based tool for mobile merged reality and virtual interaction, is currently being implemented by CURE International for mentoring of surgeons performing endoscopic third ventriculostomy-choroid plexus cauterization (https://www.helplightning.com). Such evolving technologies hold great potential for ongoing training, assessing surgical competence, and enhancing relationships among geographically isolated neurosurgeons..$^{41,42}$

\section{Challenges}

Neurosurgeons delivering care in developing countries face unique challenges. Well-developed anesthesia, intensive care unit, radiology, nursing, and oncology teams are prerequisites for the delivery of neurosurgical care in any country. ${ }^{5}$ Geopolitical stability, strong referral networks, dependable electricity, adequate equipment, and reliable postoperative follow-up are additionally required. ${ }^{20,21}$ Furthermore, even though such care is typically delivered through philanthropic efforts, the most destitute patients may be quite simply too poor to obtain even "free" subspecialty care, leading to delays in referral, poor postoperative follow-up, and delays in identifying and managing postoperative complications. ${ }^{17,18,24}$ Visiting surgeons must be attentive to the additional resources required to identify patients at highest risk. Adding yet another layer of complexity, prevailing local conception and stigmatization of pediatric neurological disability, and confidence in the local health care system, have wide variability and sometimes a dramatic influence on care delivery. $5,15,29,31$ All of these obstacles have hampered evaluation of the efficacy of delivering high-complexity neurosurgical care in the developing world. . $^{16,23,28,40}$

Many neurosurgical groups have identified and overcome these barriers through a process of trial and error. The recent ascent of surgical care as a global health priority may soon bring a more coordinated approach to the widespread, inefficient, and disjointed efforts. The "Global Surgery" movement is advocating incorporating surgical care as part of health systems strengthening-a paradigm widely accepted as the most sustainable solution. And they are succeeding - at the World Health Assembly last year, resolution 68.15, calling for "strengthening essential and emergency surgical care and anesthesia," passed unani- mously. The neurosurgical correlate to the Global Surgery movement, Global Neurosurgery, is still in its infancy. ${ }^{30}$ Yet, important and foundational work is already in progress. For example, a worldwide neurosurgery workforce and capacity mapping project is underway as a joint project of the World Federation of Neurosurgical Societies (WFNS) and the WHO, to establish a baseline and identify the areas of most need. Additionally, neurosurgeons at the Harvard Program in Global Surgery and Social Change are working to provide a centralized forum for international collaboration (https://globalneurosurgery.org/), and FIENS and the WFNS continue to improve networking and matching of experienced neurosurgeons with international partners. Repeated short-term trips by rotating surgeons, combining resources from multiple institutions with ongoing follow-up, can provide a continuity of care that a single neurosurgeon is unable to provide. In addition, short-term trips in conjunction with visiting observerships and remote telecollaboration have also proved successful for sustained partnerships and capacity building. ${ }^{6}$ Results of this survey suggest that development of an accessible, comprehensive, and updated online community of existing and potential collaborations would be valuable for surgeons seeking to initiate new relationships and find creative solutions to providing care in low-resource settings.

\section{Limitations of the Study}

There are several limitations based on our cross-sectional survey study design. Although the $35 \%$ response rate compares favorably to typical response rates in online survey studies, response bias remains a potential concern. Additionally, because we used an anonymous survey, we were unable to obtain detailed information on individual respondents. Although we could not account for potential completion of the survey by unintended participants, we believed that willful completion by individuals other than attending-level pediatric neurosurgeons in North America was unlikely and was outweighed by the value of contacting all potential participants through the AANS/CNS Pediatric Section email list. Furthermore, the objective of this study was not necessarily to reflect the full spectrum of views of the Pediatric Section membership, but rather to survey the range of ongoing international outreach efforts, and to determine perceived barriers to outreach. The selected study design was sufficient for this purpose. Although responses were most likely obtained at a higher rate from individuals with interest in and history of global neurosurgery work, we do not view this as a limitation. People who have participated in international outreach have insight and perspective that differs from those who do not engage in such outreach efforts and may be better suited to identify barriers to involvement. Nevertheless, future studies would be valuable to compare regional and practice pattern differences between neurosurgeons' involvement in international neurosurgical outreach, to more effectively target specific groups of neurosurgeons and to increase international involvement.

\section{Conclusions}

Pediatric neurosurgeons based in North America are 
currently involved in a wide range of international outreach efforts. Although interference with current practice is the most commonly cited barrier to participation, difficulty identifying international partners and lack of support are common, modifiable barriers. Broadening the range of US-based neurosurgical outreach and facilitating educational efforts requires high-level coordination across a large number of organizing entities. A centralized online community of existing projects with facilitated introductions between prospective partners would lower one barrier to participation and potentially increase the number of neurosurgeons participating in the worldwide effort to increase surgical capacity.

\section{Acknowledgments}

Dr. Davis completed this work as a Women's Leadership Council Clinical Scholar in the Department of Neurosurgery at the University of Alabama at Birmingham, supported by the Kaul Foundation.

\section{References}

1. Alkire BC, Shrime MG, Dare AJ, Vincent JR, Meara JG: Global economic consequences of selected surgical diseases: a modelling study. Lancet Glob Health 3 (Suppl 2):S21S27, 2015

2. Awori J, Strahle J, Okechi H, Davis MC: Implications of patient-borne costs associated with pediatric neurosurgical care in eastern Africa. J Neurosurg Pediatr 18:116-124, 2016

3. Bagan M: The Foundation for International Education in Neurological Surgery. World Neurosurg 73:289, 2010

4. Blankstein U, Dakurah T, Bagan M, Hodaie M: Structured online neurosurgical education as a novel method of education delivery in the developing world. World Neurosurg 76:224-230, 2011

5. Cadotte DW, Viswanathan A, Cadotte A, Bernstein M, Munie T, Freidberg SR: The consequence of delayed neurosurgical care at Tikur Anbessa Hospital, Addis Ababa, Ethiopia. World Neurosurg 73:270-275, 2010

6. Davis MC, Can DD, Pindrik J, Rocque BG, Johnston JM: Virtual interactive presence in global surgical education: international collaboration through augmented reality. World Neurosurg 86:103-111, 2016

7. Davis MC, Than KD, Garton HJ: Cost effectiveness of a short-term pediatric neurosurgical brigade to Guatemala. World Neurosurg 82:974-979, 2014

8. Dempsey RJ, Nakaji P: Foundation for International Education in Neurological Surgery (FIENS) Global Health and Neurosurgical Volunteerism. Neurosurgery 73:1070-1071, 2013

9. Dreyfus HL, Dreyfus SE: The ethical implications of the five-stage skill-acquisition model. Bull Sci Technol Soc 24:251-264, 2004

10. Duenas VJ, Hahn EJ, Aryan HE, Levy MV, Jandial R: Targeted neurosurgical outreach: 5-year follow-up of operative skill transfer and sustainable care in Lima, Peru. Childs Nerv Syst 28:1227-1231, 2012

11. Dupuis CC: Humanitarian missions in the third world: a polite dissent. Plast Reconstr Surg 113:433-435, 2004

12. El Khamlichi A: African neurosurgery: current situation, priorities, and needs. Neurosurgery 48:1344-1347, 2001

13. El Khamlichi A: Neurosurgery in Africa. Clin Neurosurg 52:214-217, 2005

14. Farmer PE, Kim JY: Surgery and global health: a view from beyond the OR. World J Surg 32:533-536, 2008

15. Folaranmi T: mHealth in Africa: challenges and opportunities. Perspect Public Health 134:14-15, 2014
16. Gathura E, Poenaru D, Bransford R, Albright AL: Outcomes of ventriculoperitoneal shunt insertion in Sub-Saharan Africa. J Neurosurg Pediatr 6:329-335, 2010

17. Grimes CE, Bowman KG, Dodgion CM, Lavy CBD: Systematic review of barriers to surgical care in low-income and middle-income countries. World J Surg 35:941-950, 2011

18. Gyedu A, Baah EG, Boakye G, Ohene-Yeboah M, Otupiri E, Stewart BT: Quality of referrals for elective surgery at a tertiary care hospital in a developing country: an opportunity for improving timely access to and cost-effectiveness of surgical care. Int J Surg 15:74-78, 2015

19. Haglund MM, Kiryabwire J, Parker S, Zomorodi A, MacLeod D, Schroeder R, et al: Surgical capacity building in Uganda through twinning, technology, and training camps. World J Surg 35:1175-1182, 2011

20. Hambrecht A, Duenas MJ, Hahn EJ, Aryan HE, Hughes SA, Waters D, et al: Strategic design for pediatric neurosurgery missions across the Western Hemisphere. Surg Neurol Int 4:62, 2013

21. Hughes SA, Jandial R: Ethical considerations in targeted paediatric neurosurgery missions. J Med Ethics 39:51-54, 2013

22. Levy ML, Duenas VJ, Hambrecht AC, Hahn EJ, Aryan HE, Jandial R: Pediatric neurosurgery outreach: sustainability appraisal of a targeted teaching model in Kiev, Ukraine. J Surg Educ 69:611-616, 2012

23. Mainthia R, Tye GW, Shapiro J, Doppenberg EMR, Ward JD: A model for neurosurgical humanitarian aid based on 12 years of medical trips to South and Central America. J Neurosurg Pediatr 4:4-9, 2009

24. Mansouri A, Chan V, Njaramba V, Cadotte DW, Albright AL, Bernstein M: Sources of delayed provision of neurosurgical care in a rural kenyan setting. Surg Neurol Int 6:32, 2015

25. Mansouri A, Ibrahim GM: Moving forward together: The Lancet Commission on Global Surgery report and its implications for neurosurgical procedures. Br J Neurosurg 29:751-752, 2015

26. Mathers CD, Loncar D: Projections of global mortality and burden of disease from 2002 to 2030. PLoS Med 3:e442, 2006

27. Meara JG, Leather AJM, Hagander L, Alkire BC, Alonso N, Ameh EA, et al: Global Surgery 2030: Evidence and solutions for achieving health, welfare, and economic development. Surgery 158:3-6, 2015

28. Munyi N, Poenaru D, Bransford R, Albright L: Encephalocele - a single institution African experience. East Afr Med J 86:51-54, 2009

29. Oyewole A, Adeloye A, Adeyokunnu AA: Psychosocial and cultural factors associated with the management of spina bifida cystica in Nigeria. Dev Med Child Neurol 27:498-503, 1985

30. Park KB, Johnson WD, Dempsey RJ: Global neurosurgery: the unmet need. World Neurosurg 88:32-35, 2016

31. Paschal AM, Ablah E, Wetta-Hall R, Molgaard CA, Liow K: Stigma and safe havens: a medical sociological perspective on African-American female epilepsy patients. Epilepsy Behav 7:106-115, 2005

32. Piquer J, Qureshi MM, Young PH, Dempsey RJ: Neurosurgery Education and Development program to treat hydrocephalus and to develop neurosurgery in Africa using mobile neuroendoscopic training. J Neurosurg Pediatr 15:552-559, 2015

33. Sedney CL, Siu J, Rosseau G, Dempsey R, Bernstein M: International neurosurgical volunteerism: a temporal, geographic, and thematic analysis of foundation for international education in neurological surgery volunteer reports. World Neurosurg 82:963-968, 2014

34. Shah S, Wu T: The medical student global health experience: professionalism and ethical implications. J Med Ethics 34:375-378, 2008 
35. Sheldon GF, Ricketts TC, Charles A, King J, Fraher EP, Meyer A: The global health workforce shortage: role of surgeons and other providers. Adv Surg 42:63-85, 2008

36. Voelker R: Experts say projected surgeon shortage a "looming crisis" for patient care. JAMA 302:1520-1521, 2009

37. Warf BC: Editorial. Neurosurgical humanitarian aid. J Neurosurg Pediatr 4:1-3, 2009

38. Warf BC: Educate one to save a few. Educate a few to save many. World Neurosurg 79 (2 Suppl):S15.e15-S15.e18, 2013

39. Warf BC, Alkire BC, Bhai S, Hughes C, Schiff SJ, Vincent JR, et al: Costs and benefits of neurosurgical intervention for infant hydrocephalus in sub-Saharan Africa. J Neurosurg Pediatr 8:509-521, 2011

40. Warf BC, Dagi AR, Kaaya BN, Schiff SJ: Five-year survival and outcome of treatment for postinfectious hydrocephalus in Ugandan infants. J Neurosurg Pediatr 8:502-508, 2011

41. Wootton R, Bonnardot L: Telemedicine in low-resource settings. Front Public Health 3:3, 2015

42. Wootton R, Geissbuhler A, Jethwani K, Kovarik C, Person DA, Vladzymyrskyy A, et al: Long-running telemedicine networks delivering humanitarian services: experience, performance and scientific output. Bull World Health Organ 90:341-347, 347A-347D, 2012

43. Wright IG, Walker IA, Yacoub MH: Specialist surgery in the developing world: luxury or necessity? Anaesthesia 62 (Suppl 1):84-89, 2007
44. Zafar SN, Fatmi Z, Iqbal A, Channa R, Haider AH: Disparities in access to surgical care within a lower income country: an alarming inequity. World J Surg 37:1470-1477, 2013

\section{Disclosures}

The authors report no conflict of interest concerning the materials or methods used in this study or the findings specified in this paper.

\section{Author Contributions}

Conception and design: all authors. Acquisition of data: Davis, Johnston. Analysis and interpretation of data: Davis, Johnston. Drafting the article: Davis, Rocque. Critically revising the article: all authors. Reviewed submitted version of manuscript: all authors. Approved the final version of the manuscript on behalf of all authors: Davis. Statistical analysis: Davis. Administrative/ technical/material support: Rocque, Singhal, Ridder, Pattisapu, Johnston. Study supervision: Rocque, Singhal, Ridder, Pattisapu, Johnston.

\section{Correspondence}

Matthew C. Davis, Department of Neurosurgery, University of Alabama at Birmingham, 1064 Faculty Office Tower, 1620 6th Ave.South, Birmingham, AL 35234.email: matthewdavis@ uabmc.edu. 